\title{
Applying Data Ming to Develop a Warning System of Procurement in Construction
}

\author{
Chun-Ling Ho and Hao-Wen Shih
}

\begin{abstract}
In the knowledge-based economy era, an enterprise need to quickly control and accumulate knowledge in a high-knowledge and complicated market and also use them to establish a proper management and warming system for decision-makers and managements. Procurements always play an important role to increase profit in the organization and an effective procurement system always increases knowledge accumulated and management of procurements as well as further feedback alarm when abnormal procurement happened. The research bases on characteristics of construction industry because of personal procurements as well as long and complicated processes. However, if the procurements could be managed or assisted and conducted by knowledge system, it not only hand over related procurement experiences of construction, but also reduces risk of procurement via effective warming system as well as promotes entire performance and profits of enterprise. Therefore, this project will consolidate software and hardware technology of information to find out association rules in knowledge of procurement between different projects from huge database of procurement by data mining technology and also develop a unique abnormal procurement alarm system for construction industry. It is expected to solve operating problems and achieve purchasing needs as well as fulfill profits expectation.
\end{abstract}

Index Terms - Construction, procurement, warning system, knowledge management, data mining.

\section{INTRODUCTION}

In the economy with knowledge, the business organization performance of operating and competitiveness are often positively related. For leading to good performance under highly competitive market, the companies must have the ability that enhances performance objectives and contribution in the organization. And how to quickly grasp and accumulation of knowledge and the use of corporate knowledge to build adaptive management in the highly complex market, the warning information system for decision-makers is the basis.

Procurement activities in an organization often play an important role in enhancing profits. Business today must also face the upheaval and diversified materials procurement of market, and effective system or platform of procurement management will help knowledge accumulation, and to further feedback abnormal warning of procurement. The products of Construction industry are different from other regularization process. For its particularity in the engineering project, process of procurement play a good or inutile key in

Manuscript received August 20, 2013; revised November 6, 2013.

The authors are with the Department of Information Management, University of Kao Yuan, Kaohsiung, Taiwan (e-mail: \{clho, t90174\}@ cc.kyu.edu.tw). the quality. Therefore, the smooth procurement relevant to overall schedule and cost reduction in the project, and how to transfer huge procurement practices through information technology into valuable knowledge has been to proceed to the task in the construction.

The research also described the four factors about measuring performance of procurement, they were "cost", "lead time", "customer satisfaction" and "quality", where "costs" was a great influence[1]. This is also an indirect response for controlling effectively costs for procurement. Therefore, the research is focus on procurement processes and to identify factors in cost characteristics, and it is helpful to build warning system for construction procurement.

\section{LITERATURE REVIEW}

Generally, life cycle of construction must include plan, design, purchase, build, maintain five stages, and to compare with other stages, purchase spends short time but however it affects whole constructing cost [2], [3]. Therefore, each activity of purchasing stage whether smoothly or not will affect whole engineering [4]. General Service Administration shows that Purchasing is a skill, the aim is to promote the purchasing units and departments under control by the laws and regulations of the specification within the scope and for required material categories, time and place to take appropriate arrangements for creating the largest economy benefits on using units and government [5], [6]. The research points out the deciding process of purchasing products and services by units include confirmation, evaluation and chosen the most proper brands and suppliers [7]. It thinks that purchasing is to gain the products by the lowest prices or costs [8].

Data mining has been successfully applied in the wide fields, such as production, manufacture, health care, finance and marketing [9]-[11]. IBM had used Fuzzy model and statistics to analyze the cases of insurance deceit and claim for health-case industry [12], [13]. Data mining is one kind of new and recycling process to make decision, support and analyze, which can discover knowledge of hidden value from data to provide enterprise professionals for the reference [14], [15]. It applied data mining to extract useful rules through the process of purification and classification from the customer transaction information stored in the database [16]. The research used data mining application technology to find out the best recommendation, which would like to explore relative information from historical data [17]. 


\section{THE METHODS OF RESEARCH}

\section{A. The Processes of Research}

As techniques of data mining have been successfully applied in various fields, this study applied association rules of data mining, which can extract hidden and useful information from the procurement database. And the other to obtain prediction functions, it is established warning module by decision tree with classification.

The research for procurement operations, it proposed an integrated mining mechanism in the procurement. It is for finding the abnormal characteristics associated with the procurement of the rule base, and to evaluate the warning from all procurement operations may occur before and carry.

The research for procurement operations, it proposed an integrated mining mechanism in the procurement. It is for finding the abnormal characteristics associated with the procurement of the rule base, and to evaluate the warning from all procurement operations may occur before and carry.

Before the execution in this study, it has first to understand the contents of the procurement process. In order to obtain effective characteristics of procurement, it combined hardware and software of technologies. And using association of data mining, it excavated related knowledge from a large number of procurement database, and further it designed and construct warning platform of procurement. The architecture of overall warning systems is shown in Fig. 1 .

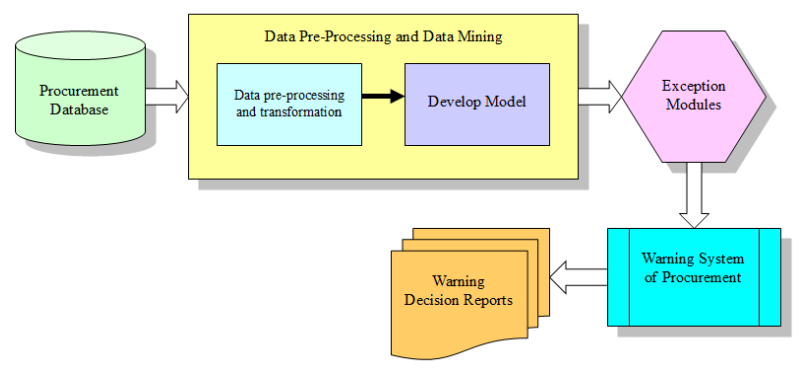

Fig. 1. The architecture of warning system in procurement.

\section{B. The Tools of Ming}

Before data mining, it must first be pretreated data from raw data with missing. Namely clearing data, it including discards unwanted data of field. And the data preprocessing and conversion including collecting relevant information to calculate the noise and then determined of the missing data and correct data type. Through data preprocessing and conversion, it meets the needs of data mining. As well through data preprocessing and conversion, it meet the requirements by data mining.

In mining phase, this study used Microsoft SQL Server 2005 as the tool of data mining. It applied SQL Server Management Studio with integrated environmental functions that can be used to access, configure, manage, and develop components such as Database Engine, Analysis Services and so on. In addition, it also applied SQL Server Business Intelligence Development Studio which has developed an integrated business intelligence environment, including Cube data sources, reports, dimensions, analysis services database. Main stages of the entire mining process include data collection, data preprocessing, data mining, modeling, evaluation and final knowledge representation. An important step in the pre-operation is data preprocessing, including data integration, data clearing, data conversion. It transferred the data into SQL Server from the original database MySQL of purchase. And through phpMyAdmin functionality of Database Manager, it transposed the original data into SQL syntax.

Next, it used iDA(from Information Acumen Corporation ) for the front-end processing, includes front-end processor (PreProcessor), data mining tools (ESX), Rule Builder (Rule Maker) and Report Builder. All mining history of the procurement, it clustered data to identify key factors of procurement practices in all affect performance and in order to provide effective decisions in purchasing.

\section{MINING FOR WARNING SYSTEM}

\section{A. Process Analysis in Purchasing}

Currently the micro system has fully standardized procurement documents, it will be contributed its knowledge base and data mining. With this micro system, it can comprehensive storage and records data for past projects, and managers can search for case-related information by electronically interface. However, it appears inadequate for knowledge-based records and warning mechanisms. Therefore, how to create a customized procurement knowledge through various types of procurement documents through will be the purpose of this research.

The Research will interview procurement staff with experience. And through purchasing behavior, principles, procedures and relevant basis, it expressed the current the model of procurement. Their views are summarized as follows in the Table I.

In summary, the study found that procurement officers expect customized system that brings benefits to the procurement, including the following points.

1) Sharing resource across units in order to save the time of purchasing.

2) Standard and electronic procurement documents to synchronized storage and quick access.

3) The establishment of knowledge base for fast purchasing decisions.

4) To improve benefits costs and time in new staff training of the procurement.

5) Synchronously to share information, store information of procurement.

6) Records and notifications of abnormal changes in procurement activities.

\section{B. Data Mining for Procurement}

This study adopted Case Method of Non-Experimental method, and used In-depth-Interview of Qualitative Technique through small-scale exploratory study. It interviewed face to face with buyers to collect data and summarized and analyzed, including the characteristics explained, data collected, the phenomenon of knowledge analyzed and the system design and introduction.

Trying to find an optimum mold for the problems in the 
status of procurement, it obtained valid information and characteristics through large amounts of data mining, and contains three major elements: data preprocessing, data mining and knowledge representation.

TABLE I: THE VIEWS OF PROCUREMENT STAFF

\begin{tabular}{|c|c|}
\hline Staff & Existing procurement mode or system recommendations \\
\hline Staff A & $\begin{array}{l}\text { 1. The performance of procurement will directly affect } \\
\text { the profits of cooperation, thus the process of } \\
\text { procurement modified or rebuild need to be } \\
\text { considered. } \\
\text { 2. It is connected between performances of procurement, } \\
\text { value created and costs, and the performance } \\
\text { expressed is based on procurement experience } \\
\text { accumulated and well judgment. So it is important to } \\
\text { standardize for knowledge-decided procurement and } \\
\text { will upgrade the quality of process. }\end{array}$ \\
\hline Staff B & $\begin{array}{l}\text { 1. During numerous and time-limited procurement, } \\
\text { usually accompany with defects. If it could conduct } \\
\text { into more efficiency information tools and simplify } \\
\text { and automation the process, the time will be reduced. } \\
\text { 2. It is urgent to build knowledge index, and to convert } \\
\text { procurement experience to be recorded and inquired. It } \\
\text { also could reduce mistakes by human error or business } \\
\text { handover via process standardize. }\end{array}$ \\
\hline Staff C & $\begin{array}{l}\text { 1.It is very important to inherit the procurement } \\
\text { experiences and management of knowledge module } \\
\text { established will help upgrade quality and efficiency of } \\
\text { the procurement process. } \\
\text { 2.It is suitable to conduct the information tools or system } \\
\text { into procurement-knowledge and also via } \\
\text { accumulation, proliferation, transfer and heritage could } \\
\text { avoid experience lost. }\end{array}$ \\
\hline Staff D & $\begin{array}{l}\text { 1. Currently, the supplier management and procurement } \\
\text { process will directly affect the procurement } \\
\text { performance, so how to according to different } \\
\text { procurement content to make a customized } \\
\text { procurement process and follow-up contract managed } \\
\text { could significantly shorten the procurement } \\
\text { lead-time. } \\
\text { 2. Through guided knowledge system, the buyer could } \\
\text { quickly input the demand, and the system could make } \\
\text { an optimized matching in accordance with } \\
\text { experiences or supplier properties to not only avoid } \\
\text { mistakes by human error or a long lead-time but also } \\
\text { promote the procurement performance. }\end{array}$ \\
\hline
\end{tabular}

\section{Develop the Warning System of Procurement}

The research selected a three-tier logical architecture to be the architecture of systems, including database layer, logic layer and the presentation layer. Database layer stored in SQL Server through the collating data and the converted, the other logical processing layer dealt with mining tools, and finally users of the system to get the tables and graphical information of decision through the presentation layer with ASP.NET Web application.

Abnormal module of procurement is obtained the features, knowledge and the association of exception by data mining, which includes the abnormal cost with association rules, anomalies time and anomalies quality. It is different from module procurement in the past and to be a new feature module for knowledge-based procurement in management and performance control. Forecasting model establishment is the key works for warning systems. It will identify and predict the exception of procurement based on models with parameters input. If it gets abnormal phenomenon, the system will determine the way to present the warning action by decision-tree. Namely it conducts segmentation recursively, and calculates to find the greatest information gain by using Entropy. Creation mode is concerned, and the basic steps that will be analysis on purchasing behavior to predict and the use of appropriate mathematical methods for various parameters and evaluation in the prediction model. The warning system of procurement is shown in Fig. 2.

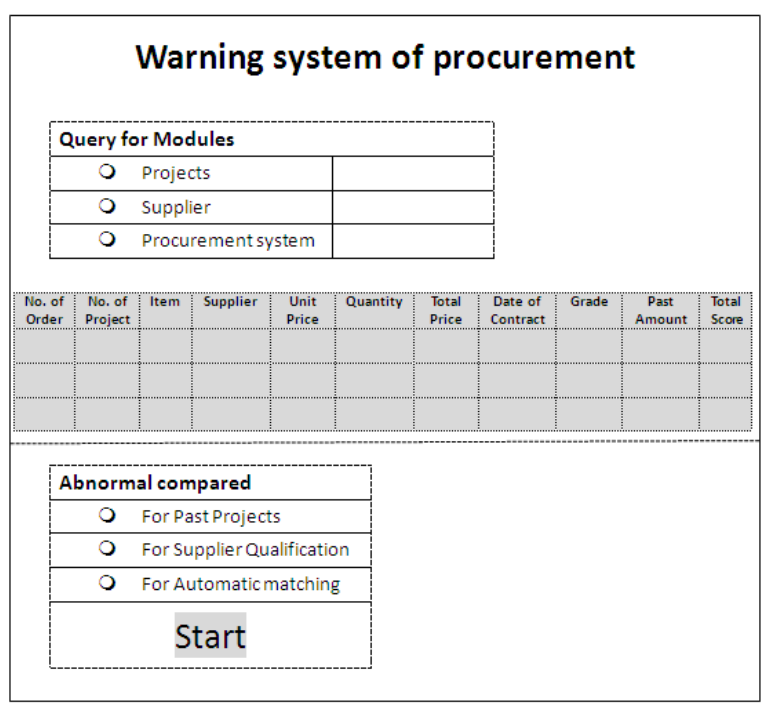

Fig. 2. The warning system of procurement.

\section{CONClusions}

Based on the properties of construction, the procurement practices have highly professional feature. Procurement in terms of strategic planning, inquiry, bargain technical operation and even the quality, quantity, delivery and cost management, it must be exhaustive. Although complex processes of procurement, it can inheritance experience and knowledgeable operations. In addition, it can reduce procurement risk and enhance overall performance profit by knowledge system. Therefore, the effective management and control of procurement will have a decisive impact for construction projects.

Based on this, the study is divided into two parts. The first part is focused on "procurement practices and processes" with in-depth discussions, and then extract valuable characteristic from the years database of procurement through introduction of the information technology tools. In the second part, it presents "knowledge of procurement" for the development. In order to construct warning system of procurement, it customized purchasing behavior and reduced poor risks through performance control as well as before the occurrence of abnormality. The warning system could be as reference for procurement management and control before exception occurs.

\section{ACKNOWLEDGMENT}

Then author would like to acknowledge the National Science Council, Taiwan, for financially supporting this work under contract No. NSC-100-2622-E-244-005-CC3.

\section{REFERENCES}

[1] L. M. Ellram and A. Carr, "Strategic purchasing: A history and review," International Journal of Purchasing and Materials Management, vol. 30, no. 1, pp. 9-19, March 1994 
[2] S. Dowlatshahi, "Designer-buyer-supplier interface: Theory verus practice," Int. J. Production Economics, vol. 63, pp. 111-130, 2000.

[3] K. N. Thompson, "Vendor profile analysis," Journal of Purchasing and Materials Management, pp.11-18, 1990.

[4] C. Wei, S. Piramuthu, and M. J. Shaw, Knowledge discovery and data mining to appear in handbook of knowledge management, Springer-Verlag, 2002.

[5] S. F. Heinritz and P. V. Farrell, "Purchasing principle and applications,” N. J, Printice-Hall, 1992.

[6] E. B. Louis and D. L. Kurtz. (1992). Management. [Online]. Available: http://en.wikipedia.org/wiki/Management

[7] M. Leenders, H. Fearson, and W. England, "Purchasing and materials management," IRWIN, vol. 8e, 1985.

[8] G. J. Zenz, Purchasing and the management of materials, John Wiley \& Sond, New York, 1981.

[9] R. J. Brachman, T. Khabaza, W. Kloesgen, G. P. Shapiro, and E. Simoudis, "Mining business databases," Communication of the ACM, vol. 39-11, pp. 42-48, 1996.

[10] S. Daskalaki, I. Kopanas, M. Goudara, and N. Avouris, "Data mining for decision support on customer insolvency in telecommunications business," European Journal of Operational Research, vol. 145, no. 2, pp. 239-255, 2003.

[11] R. Agrawal, T. Imielinski, and A. Swami, "Mining association rules between sets of items in large data bases," in Proc. the ACM Sigmod Conference on Management of Data, Washington DC, USA, pp. 1-11, 1993.

[12] U. Fayyad and G. P. Shapiro et al., "From data mining to knowledge discovery in databases," American Association for Artificial Intelligence, vol. 17, pp. 37-54, 1996.

[13] C. Hall, "The devil's in the details: Techniques, tools, and applications for database mining and knowledge discovery," Intelligent Software Strategies, vol. 11-9, pp. 1-16, 1995.

[14] J. Han and M. Kamber, Data mining: Concepts and techniques, Morgan Kaufmann Publishers, San Francisco, 2000.

[15] P. Buxmann and J. Gebauer, "Evaluating the use of information technology in inter-organizational relationships," in Proc. the 32nd Annual Hawaii on Systems Science, pp. 12-14, 1999.

[16] P. Zdzislaw, "Rough sets and intelligent data analysis," Information Sciences, vol. 147, pp. 1-12, 2002

[17] C. Kleissner, "Data mining for the enterprise," in Proc. the Thirty-First Hawaii International Conference, pp. 295-304, 1998.

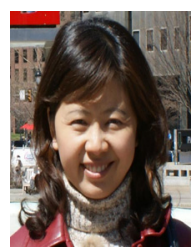

mining.

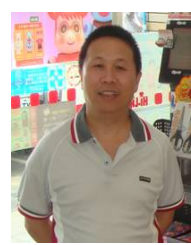

Chun-Ling $\mathrm{Ho}$ is an assistant professor of information management at Kao Yuan University (KYU) in Taiwan. Before joining KYU, she worked as a senior director of project management in construction. She received her MS(1995), and $\mathrm{PhD}(2010)$ in civil engineering from National Chiao Tung University, Taiwan. Her research interests and publications are in the areas of information technology, artificial intelligence, e-learning and data

Hao-Wen Shih is an assistant professor of information management at Kao Yuan University (KYU) in Taiwan. His research interests are in the areas of decision support systems, fuzzy theory and information technology. 